\title{
UNA MIRADA AL CASO DEL PALACIO DE JUSTICIA DESDE LA RESPONSABILIDAD DEL ESTADO FRENTE A LOS DERECHOS HUMANOS. UNA APROXIMACIÓN A UN ESTADODELARTE
}

\section{A look at the case of the Palace of Justice from the responsibility of the State in the face of human rights. An Approach to a State of the Art}

Rodolfo Torregrosa Jiménez*

María Hilda Triviño**,

Norhys Torregrosa Jiménez***

Recepción: 16 de agosto de 2017. Aceptación: 24 de septiembre de 2017.

DOI: http://dx.doi.org/10.21017/Rev.Repub.2017.v23.a35

\section{RESUMEN}

Este documento tiene como propósito contestar la pregunta: ¿Qué responsabilidad tuvo el Estado colombiano en el caso del Palacio de Justicia? Se realiza una revisión bibliográfica de los documentos que se han escrito sobre el tema y se elaboran tres categorías para facilitar el rastreo bibliográfico. Para esto, la investigación utiliza una metodología cualitativa que tiene como técnica el análisis documental, y el instrumento es la elaboración de fichas bibliográficas. La principal conclusión es que los temas específicos de los trabajos de investigación se dirigen, en mayor medida, a hacer un relato de los sucesos acaecidos en el Palacio de Justicia, un análisis de los hechos planteándolo como acto terrorista, y como en este se violaron derechos humanos tanto a los empleados del palacio como a los mismos integrantes del grupo armado que realizó la toma.

Palabras clave: Palacio de Justicia, responsabilidad estatal, derechos humanos.

\section{ABSTRACT}

This document aims to answer the question: ¿What responsibility did the Colombian State have in the case of the Palace of Justice? Carrying out a

* Economista. Doctor en Sociología Jurídica e Instituciones Políticas. Docente investigador de la Corporación Universitaria Republicana.

** Abogada. Universidad Libre. Magíster en Derecho Administrativo.

*** Politóloga, doctora en Derecho, Universidad Externado de Colombia. Docente investigadora, Universidad Libre. 
bibliographical revision of the documents that have been written on the subject and elaborating three categories to facilitate the bibliographic tracing. For this, the research uses a qualitative methodology that has as technique the documentary analysis and instrument, the elaboration of bibliographic fiches. The main conclusion is that the specific topics of the research work are directed, to a greater extent, to make an account of events in the Palace of Justice, an analysis of the facts as a terrorist act, and as they were violated in this Rights to both the employees of the palace and the members of the armed group that made the decision.

Key words: Palace of Justice, state responsibility, human rights

\section{INTRODUCCIÓN}

La toma del Palacio de Justicia fue catalogada como un delito de lesa humanidad; dicho pronunciamiento vuelve este acontecimiento en un tema estudiado por la academia frente al acuerdo que busca terminar el conflicto armado colombiano. Este documento tiene como propósito contribuir a la discusión presentando una revisión de literatura sobre un tema que ha sido debatido durante más de 30 años, frente a la pregunta: ¿Qué responsabilidad tuvo el Estado colombiano en el caso del Palacio de Justicia? De esta manera, esta investigación utiliza una metodología cualitativa que tiene como técnica el análisis documental, y como instrumento, la elaboración de fichas bibliográficas.

En este contexto, las investigaciones presentan diferentes conclusiones en las categorías que ayudan a entender esta responsabilidad. Se enfatiza precisamente esta revisión en temas de responsabilidad del Estado, desaparición forzada, tortura, ejecución extrajudicial y falta de prevención y protección del Estado.

Esta revisión de la literatura se divide en tres grandes categorías: Responsabilidad del Estado, Derechos Humanos en América Latina y Toma del Palacio de Justicia. Dichas categorías fueron rastreadas en diferentes bases de datos y bibliotecas, como la Biblioteca Luis Ángel Arango, la cual es la que contiene mayor número de referencias bibliográficas sobre las tres categorías antes mencionadas.

Las categorías seleccionadas para esta revisión fueron elaboradas por la importancia que tienen para investigaciones futuras que se realicen sobre el tema escogido.

La categoría Toma del Palacio de Justicia, ya que se refiere a hechos acaecidos hace 30 años, se elaboró puesto que dicha toma es un acto de guerra dentro del 
conflicto armado que vivía el país y ha sido objeto de reflexión desde distintas perspectivas; frente a este tema se acusa una debilidad en la labor de reflexión teórica por parte de académicos, específicamente en los temas jurídicos.

La categoría Responsabilidad del Estado, toda vez que la misma, desde hace un tiempo, ha consolidado una estructura que contiene profundas temáticas, tanto en el orden económico y social, como en el ámbito jurídico, que implican diferentes títulos de imputación de la responsabilidad.

Finalmente, la categoría de Derechos Humanos en América Latina se justifica en la medida en que órdenes alternativos con pretensiones soberanas no se han definido por una verdadera norma de respeto y reconocimiento a los derechos fundamentales de quienes viven bajo su dominio. Se necesita una nueva organización de carácter autoritario que exija lealtad y obediencia incondicional, a cambio de la protección de los derechos humanos.

\section{HALLAZGOS}

Se encontraron 191 fuentes de información, entre revistas de opinión, revistas especializadas, videos, libros, monografías e informes de investigación. En la Biblioteca Luis Ángel Arango se encontró el mayor número de literatura puesto que se hallaron un total de ciento setenta y seis (176) documentos, y en la Universidad Libre se encontraron quince (15) documentos (gráfico 1).

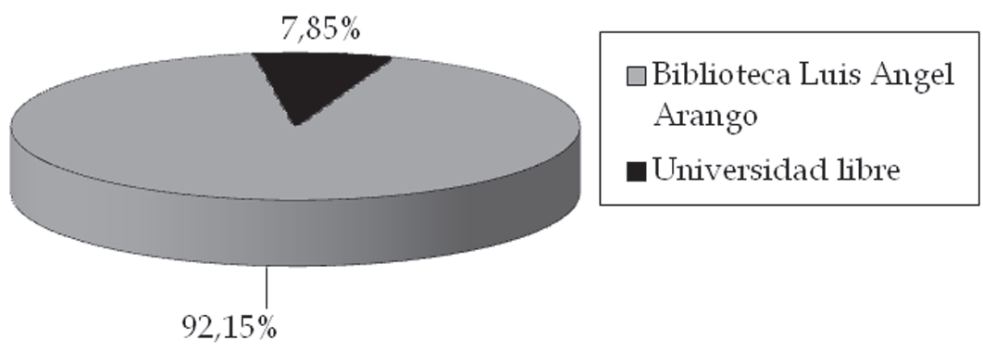

Fuente: Elaboración propia.

Gráfico 1.

Las precitadas fuentes de información encontradas han sido formuladas y desarrolladas en su mayoría en Bogotá y Medellín, y en menor proporción en otras ciudades, haciéndose esto evidente especialmente en la categoría de derechos humanos. 
Los documentos sobre el Palacio de Justicia, la responsabilidad del Estado y derechos humanos en América Latina son, en su mayoría, de tipo cualitativo y análisis específicos. Entre ellos se resaltan los comparativos, teóricos y descriptivos. En menor medida se presentan investigaciones de corte cuantitativo (gráfico 2).

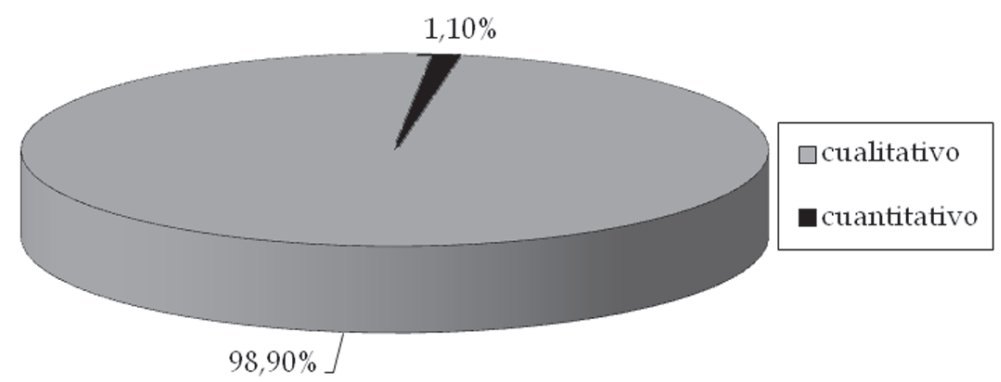

Fuente: Elaboración propia.

\section{Gráfico 2.}

Las investigaciones cualitativas con enfoque sociojurídico son las más comunes; también se encuentran estudios históricos, jurídicos y sociológicos. La investigación cuantitativa sobre las categorías seleccionadas es variada y enfocada hacia un tema en especial, los análisis estadísticos y comparativos. Ciento veintiocho (128) de los textos rastreados no son productos de investigación, y son generalmente ensayos, revistas, estudios generales, entre otros, referidos a las categorías investigadas.

La producción investigativa ha tenido como objeto de estudio, actores, situaciones y contextos nacionales e incluso internacionales. Esta ha sido impulsada principalmente por universidades, institutos y centros de estudios académicos, entidades públicas y, en menor medida, por instituciones internacionales.

La categoría de análisis que identificamos como la más desarrollada por los estudios académicos es responsabilidad del Estado con un total de ciento ocho (108) documentos; en la categoría toma al Palacio de Justicia se hallaron cuarenta y cuatro (44) escritos; se destacan poco los estudios sobre Derechos Humanos en América Latina -39- (gráfico 3).

\section{Categoría: Toma del Palacio de Justicia}

Se registró un total de cuarenta y cuatro (44) publicaciones que tienen relación directa con la categoría toma al Palacio de Justicia en el periodo de 1985 a 2016. Cuatro (4) de estas corresponden al 9,09\% y son producto de investigación; 


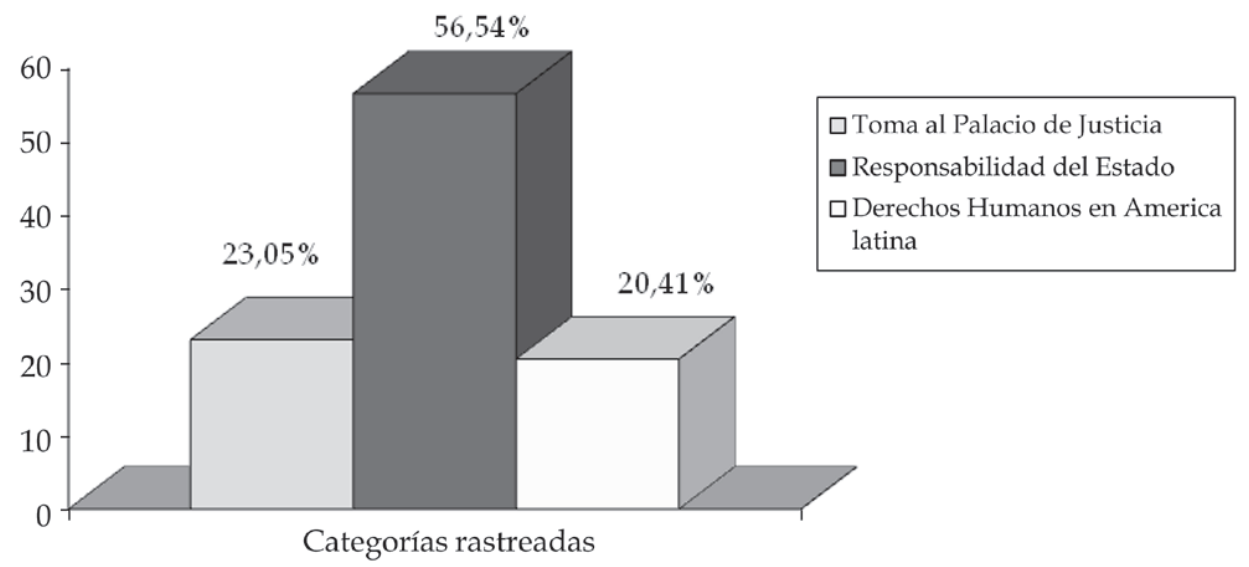

Fuente: Elaboración propia.

\section{Gráfico 3.}

treinta y ocho (38), equivalentes al $86,36 \%$, son otros trabajos no resultados de investigación, y no se tiene información de dos (2) trabajos correspondientes al $4,55 \%$ de los textos rastreados (gráfico 4 ).

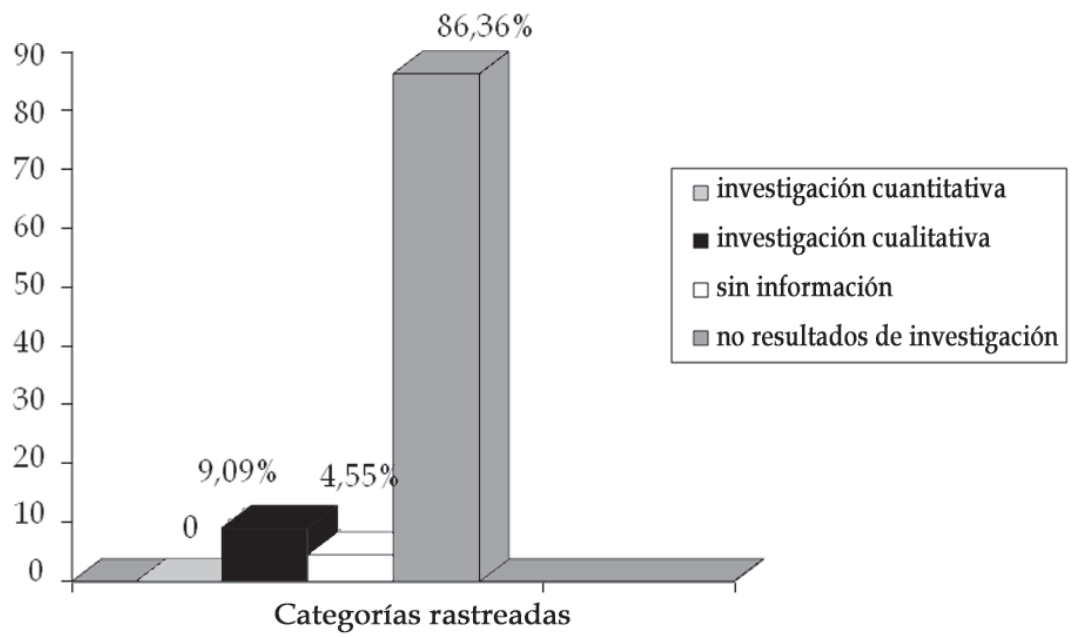

Fuente: Elaboración propia.

\section{Gráfico 4.}


En la Biblioteca Luis Ángel Arango se encuentra el mayor número de fuentes de información sobre el tema con un total de cuarenta y un (41) ejemplares, seguida por la Universidad Libre con tres (3) textos.

Entre sus autores, la mayoría son periodistas, profesionales del área de Historia y en mayor porcentaje investigadores de centros universitarios; otros son simplemente profesionales, especialistas y magísteres en diferentes ciencias y disciplinas.

Las investigaciones nacionales identificadas son realizadas en su mayoría en la ciudad de Bogotá en instituciones como la Universidad Javeriana, específicamente en la facultad de Historia, y privadas como en estudios periodísticos, cabinas de radio. Seguidamente se identifican las investigaciones realizadas por algunos claustros académicos de la ciudad Bogotá, y por entes no gubernamentales. En menor medida se encuentran investigaciones realizadas en otras ciudades del país, entre las que se encuentran Medellín.

Existen varias temáticas relacionadas con el estudio de la toma del Palacio de Justicia; algunas de ellas son¹:

- El recuento de los hechos efectuado por los familiares de las víctimas.

- La impunidad y el derecho a la justicia y a la verdad.

- La reparación del daño desde una perspectiva penal.

Las investigaciones sobresalientes en esta categoría son cualitativas, principalmente de enfoque sociojurídico; de igual modo, se identifican análisis específicos de carácter comparativo, descriptivo, diagnóstico y metodológico. Por otra parte, se encuentran investigaciones con enfoque jurídico e histórico.

Las ciencias sociales y algunas de sus disciplinas han sido el punto de partida para investigar y reflexionar sobre el tema de la administración de justicia; entre ellas se encuentran: la Filosofía, la Sociología, la Política, la Antropología,

1 Véase: Amaya, A. F. (2006). La toma del palacio de justicia: la reparación del daño en eventos de violación de derechos humanos. Vniversitas (112), 317-349; Carrisoza, M., Cordi, J., Ospina, C., Serje, M. C., y Guerrero, C. I. (1985). Condicionamientos históricoestructurales de la toma del Palacio de Justicia. Revista Vniversitas, (14), 19- 27; Behar, O. (1988). Noches de humo: como se planeó y ejecutó la toma al Palacio de Justicia. Colombia: Editorial Planeta; Jiménez, C. (1986). El Palacio de Justicia y el derecho de gentes. Bogotá: La Procuraduría; Leal, S. (2013). El holocausto del Palacio de Justicia: nombres, versiones y desacuerdos. Bogotá: Universidad Nacional de Colombia. 
la Historia y el Derecho. Los estudios jurídicos han sido constitucionales, procesales y de técnica normativa.

El 86,36\%, equivalente a treinta y ocho (38) de los textos encontrados, no es resultado de investigación, y corresponde a ensayos, artículos de opinión, ponencias, recopilaciones, propuestas y proyectos elaborados por periodistas e historiadores. En estos documentos se exponen temáticas como los sucesos ocurridos durante el 6 y el 7 de noviembre de $1985^{2}$.

\section{Categoría: Responsabilidad del Estado}

Es la segunda categoría con mayor existencia de fuentes de información en las bibliotecas seleccionadas. Se registró un total de ciento ocho (108) documentos sobre el tema, publicados en el periodo 1948 a 2016. De estos, catorce (14) corresponden al $12,96 \%$ que son productos de investigación; sesenta y cuatro (64) que corresponden al 59,25\% son otros trabajos no resultados de investigación; de los treinta (30) que corresponden al $27,77 \%$, no se tiene información de los textos rastreados (gráfico 5).

Ciento dos (102) de los documentos fueron ubicados en la Biblioteca Luis Ángel Arango, el centro documental más grande a nivel nacional, y en la Biblioteca de la Universidad Libre se hallaron seis (6) documentos. En las otras

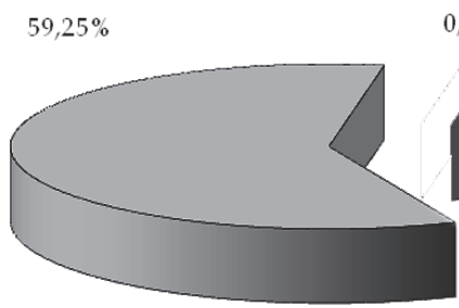

Fuente: Elaboración propia.

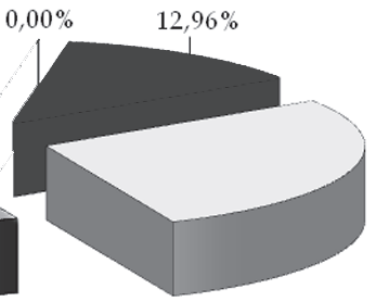

$27,77 \%$ $\square$ investigación cuantitativa

- investigacóncualitativa

$\square \sin$ información

$\square$ no resultados de investigación

\section{Gráfico 5.}

2 Véase: Behar, O. (2010). Noches de Humo, Revista Nueva Época, 16 (35), 212-227; Behar, O. (1985- 1986). Las Guerras de la Paz. Colombia: Editorial Planeta; Los dos días que conmovieron a Colombia: un año después de la toma del Palacio de Justicia aún quedan interrogantes de muy difícil respuesta. (1986). Guión, (477), 20-25; Noticiero Todelar. (2006). Buscando la verdad [registro sonoro 1 compact disc]. Bogotá; Acosta, M. (Director). (2012). El Palacio de Justicia [DVD]. Bogotá: FM Entretenimiento; Echeverry, A. (2007). La toma del Palacio de Justicia. Semana, (1314), 28-29; Jiménez, R. (1999). Toma del Palacio de Justicia: noviembre 6 de 1985. Revista Credencial Historia, (117), 14. 
bibliotecas seleccionadas la información está duplicada porque son iguales las fuentes de información.

La información sobre esta categoría es diversa; principalmente se ubica en $\operatorname{libros}^{3}$, capítulos de libros y revistas especializadas ${ }^{4}$. En menor medida se encuentra en tesis y revistas de opinión.

Los títulos reconocidos sobre responsabilidad del Estado se centran en exponer y explicar qué se entiende por responsabilidad del Estado, desarrollo del concepto de responsabilidad en la historia internacional y nacional, los elementos de la responsabilidad, los diferentes títulos de imputación de la responsabilidad, sustento constitucional y normativo de la responsabilidad del Estado, reparación del daño y concepto de reparación integral.

Las investigaciones identificadas son en su mayoría nacionales, especialmente de las ciudades de Bogotá y Medellín. En otras ciudades se identifican pocas investigaciones.

Por otra parte, se aprecia que las investigaciones proliferaron en momentos como el cambio constitucional en 1991, la toma del Palacio de Justicia en 1985 en medio de un proceso de paz con el M-19, el periodo de lucha contra el narcotráfico y el sicariato en la década del 90, el proceso de paz con las FARC en el año 2000 y el proceso de desmovilización de los paramilitares en el año 2003, y diálogos de paz en la Habana en el año 2014.

La mayor parte de los autores son docentes e investigadores de diferentes universidades del país o de organizaciones no gubernamentales.

3 Véase: Carrillo, J. M. (2001). La Responsabilidad Administrativa. Bogotá: Universidad Externado de Colombia; Ruiz, W. (2011). Responsabilidad del Estado legislador. Bogotá: Universidad Libre; Pinzón, C. E. (2015). El derecho de daños en la responsabilidad extracontractual del Estado. Bogotá: Ediciones Doctrina y Ley; Ocampo, Y. (2015). La responsabilidad del Estado legislador: frente a la expedición de normas inconstitucionales. Bogotá: Leyer Editores; Gil, E. (2015). Tesauro de responsabilidad extracontractual del Estado: jurisprudencia 2012-2014. Bogotá: Editorial Temis; Gil, E. (2010). Responsabilidad extracontractual

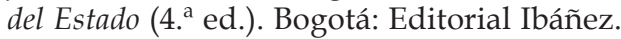

4 Véase: Gamboa, E. (2014). La carga de mitigar los daños en el régimen colombiano de la responsabilidad civil extracontractual. Revista de derecho privado, (51), 1-23; Alonso, M. C. \& Leiva, E. (2012). La responsabilidad del Estado por la actividad del legislador. Revista derecho del Estado, (29), 145-173; Gil, E. (2005). Responsabilidad del Estado colombiano por los daños ocasionados por actos terroristas. Estudios de derecho, 62(139), 147- 173; Güechá, C. N. (2012). Falla en el servicio: una imputación tradicional de responsabilidad del Estado. Prolegómenos derecho y valores, 15 (29), 95-109. 
Las temáticas más representativas son ${ }^{5}$ :

- Responsabilidad del Estado por actos terroristas.

- Responsabilidad del Estado por falla del servicio.

- Responsabilidad extracontractual del Estado.

- Responsabilidad del Estado por el actuar de sus funcionarios

- Responsabilidad del Estado por los daños ocasionados.

- Responsabilidad contractual del Estado.

- Responsabilidad del Estado ante organismos internacionales.

Con respecto a esta categoría, la literatura internacional es amplia especialmente en Francia, la cual es tomada por los autores colombianos como referencia en sus escritos.

Los estudios e investigaciones referenciados corresponden, en gran parte, a estudios jurídicos; se observan, en menor medida, históricos. Todas ellos son cualitativos; además, prevalecen los análisis sociojurídicos sobre los históricos, los analíticos descriptivos, analíticos críticos y argumentativos documentales, y hay pocas fuentes de análisis cuantitativos sobre responsabilidad del Estado. Estos han tenido como principales objetos de estudio los siguientes temas ${ }^{6}$ :

5 Véase: Gil, E. (2013). Responsabilidad extracontractual del Estado (6. ${ }^{a}$ ed.). Bogotá: Editorial Temis; García, L. G. (2003). La responsabilidad patrimonial del Estado por actos terroristas. Medellín: Universidad de Medellín; Henao, J. C. (2007). El daño. Colombia: Universidad Externado; Güechá, C. N. (2012). Responsabilidad del Estado por actos de terrorismo. Bogotá: Grupo Editorial Ibáñez; Leiva, E. (2010). Responsabilidad del Estado por el hecho del legislador: análisis jurisprudencial y doctrinal. Bogotá: Grupo Editorial Ibáñez; López, J. (2007). Responsabilidad del Estado por error judicial (2. ${ }^{a}$ ed.). Bogotá: Ediciones Doctrina y Ley.

6 Véase: Gamboa, E. (2014). La carga de mitigar los daños en el régimen colombiano de la responsabilidad civil extracontractual. Revista de derecho privado, (51), 1-23; Ruiz, W. (2005). Responsabilidad del Estado legislador. Civilizar ciencias Sociales y Humanas (9), 1-22; Henao, J. C. (2007). El daño: análisis comparativo de la responsabilidad extracontractual del Estado en derecho colombiano y francés. Bogotá: Universidad Externado de Colombia; Serrano, L. G. (2014). La responsabilidad patrimonial del Estado. Bogotá: Ediciones Doctrina y Ley. 
- La carga de mitigar los daños.

- Responsabilidad del estado patrimonial del Estado legislador.

- Teoría y crítica de la responsabilidad del Estado por el daño.

El 59,25\% de los textos rastreados no son resultados de investigación; estos son tipo ensayo, compilaciones, estudios teóricos, entre otros, sobre temas de la responsabilidad del Estado a nivel nacional, además de reflexiones conceptuales sobre las teorías de la responsabilidad, entre otros ${ }^{7}$.

Categoría: Derechos humanos en América Latina

Es la tercera y última categoría rastreada. Es una variable poco tratada por académicos e investigadores, a diferencia del estudio de las de la toma al Palacio de Justicia y la responsabilidad del Estado. Se hallaron un total de treinta y nueve (39) documentos publicados en el periodo 1979 a 2016. Siete (7) de estos que corresponden al 17,94\% y son productos de investigación, treinta y dos (32), es decir, el $82,05 \%$, son otros trabajos no resultados de investigación, (gráfico 6). De estos documentos, treinta y tres (33) se encuentran en la Biblioteca Luis Ángel Arango y seis (6) se encuentran en la Biblioteca de la Universidad de Libre.

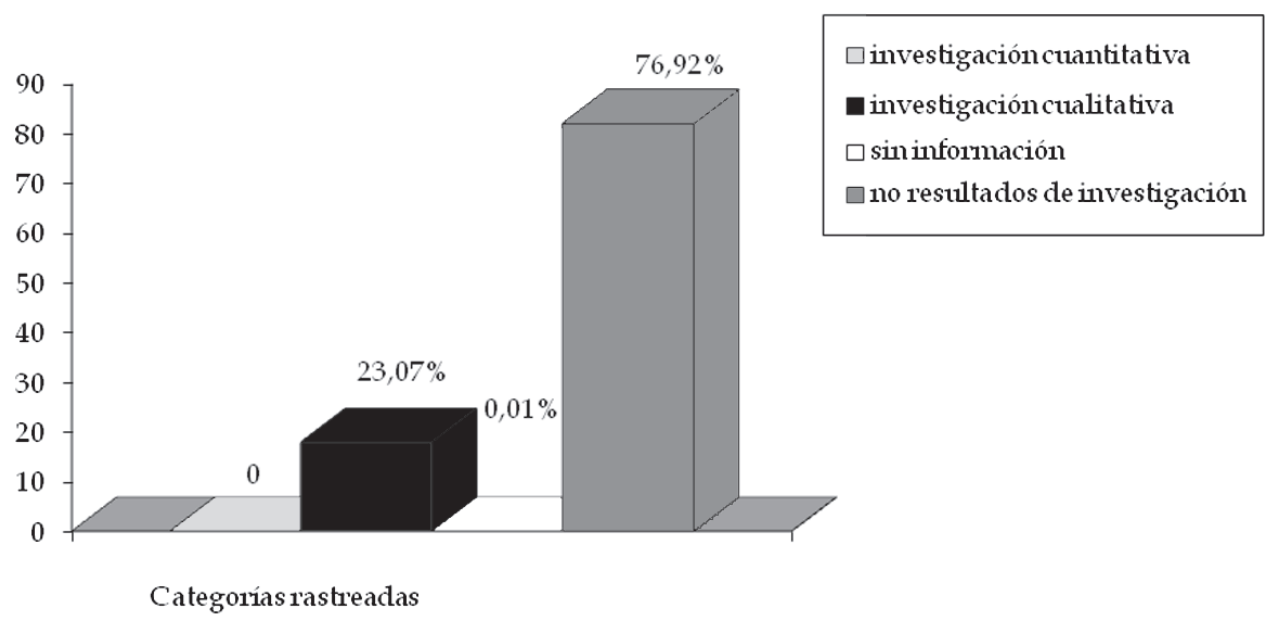

Fuente: Elaboración propia.

\section{Gráfico 6.}

7 Véase: Ruiz, W. (2010). Responsabilidad del Estado y sus regímenes. Bogotá: Ecoe Ediciones; Ruiz, W. (2013). Responsabilidad del Estado y sus regímenes (2. ${ }^{a}$ ed.). Bogotá: Ecoe Ediciones. 
Se observa que los textos fichados en la Biblioteca Luis Ángel Arango traen conceptos de derechos humanos, situaciones como la violación de derechos humanos, análisis normativo y la dinámica de los grupos guerrilleros y paraestatales en los países latinoamericanos. Con respecto a los documentos encontrados en la Biblioteca de la Universidad Libre, se trata de resultados de investigaciones y estudios sociojurídicos.

Los resultados de investigación son nacionales y se distinguen pocos estudios teóricos internacionales sobre el derecho de gentes, el cual reflexiona sobre los derechos humanos básicos, los derechos de los ciudadanos en la democracia liberal ${ }^{8}$. Las investigaciones en su mayoría se han realizado en la ciudad de Bogotá y en menor proporción en otras ciudades por instituciones universitarias. En orden de aparición se destacan algunos estudios científicos sobre derechos humanos, su importancia y aplicación? .

El interés de investigadores y académicos, profesionales de ciencias y disciplinas sociales como Sociología, Política y Derecho ha sido reflexionar sobre la importancia de los derechos humanos en Latinoamérica, los procesos de esclarecimiento y ajusticiamiento de crímenes, la condición de las víctimas y la intervención justa del conflicto armado para el caso colombiano.

Estas investigaciones han sido impulsadas por universidades, centros de investigaciones de universidades y entidades privadas ${ }^{10}$.

La investigación que se ha realizado sobre esta categoría de análisis es de tipo cualitativo. También son notables los análisis teóricos y comparativos e históricos. Los productos no investigativos son conferencias y estudios generales de derechos humanos ${ }^{11}$.

8 Véase: Verduga, C. (1988). Democracia y derechos humanos en América Latina. Quito: Ediciones Culturales UNP; Montoya, C. (2010). Alianzas entre medios de comunicación y Organizaciones de la Sociedad Civil: balances y propuestas para fortalecer la democracia y los derechos humanos en América Latina. Bogotá: Universidad Javeriana; Rodríguez, E. (1989). Democracia y derechos humanos en América Latina. Madrid: Instituto de Cultura Iberoamericana, Ediciones de Cultura Hispánica.

9 Véase: Velásquez, J. D. (2013). El derecho natural en la declaración de los derechos humanos. Revista Facultad de Derecho y Ciencias Políticas, 43 (119), 735-772; Suárez, J. J. (2013). Derechos humanos y naturaleza humana una cuestión no superada. Díkaion, 22 (2), 181-185.

10 Véase: Ureña, R. (2013). Luchas locales, cortes internacionales: una exploración de la protección multinivel de los derechos humanos en América Latina. Revista Derecho del Estado, (30), 301- 328; Botero, J. F. (2011). Derecho penal internacional protector de los derechos humanos. Revista de relaciones internacionales, 6 (1), 169-190.

11 Véase: Derechos humanos en América Latina. (1993). Perfiles Liberales, 42, 32; Rojas, S. A. (1993). Democracia y derechos humanos en América Latina: perspectivas para la próxima década. Perfiles Liberales, 7 (31), 72-79. 
Algunas de las temáticas distinguidas en los textos hallados y que son relacionadas con la categoría de análisis son: ${ }^{12}$

- Derecho internacional de los derechos humanos.

- Derechos humanos, principio universal.

- Instrumentos de protección de los derechos humanos.

- Organismo del sistema interamericano.

Las producciones resultado de investigación ${ }^{13}$ se caracterizan por centrarse en temas referentes a los procesos de crímenes de lesa humanidad, política criminal y derecho penal, así como la protección de los derechos humanos.

\section{ANÁLISIS DE LOS RESULTADOS}

Los estudios realizados por los diferentes autores son tratados a nivel nacional; su ámbito de aplicación también tiene un carácter nacional, porque toca temas jurídicos de relevancia en el sistema normativo del Estado colombiano.

Las publicaciones identificadas como resultado de investigación son diversas. Proliferan monografías de grado para optar por los títulos de sociólogo, historiador y abogado; también se encuentran reportajes periodísticos e investigaciones de más alto nivel, que toman como referente central las problemáticas y el conflicto en las ciudades colombianas, haciendo en énfasis en los sucesos del 6 y 7 de noviembre en el Palacio de Justicia, para explicar la responsabilidad del Estado por violación a los derechos humanos.

Las fuentes documentales encontradas corresponden a investigaciones realizadas durante el periodo 1948-2016, las cuales trabajan tres categorías diferentes

12 Véase: Abelló, R. (2015). Derecho internacional: varias visiones, un maestro. Bogotá: Editorial Universidad del Rosario; Camargo, P. P. (2013). Derecho Internacional Humanitario (5. a . Ed.). Bogotá: Editorial Leyer; Martin, C., Rodrigo, D., Y Guevara, J. A. (2004). Derecho internacional de los derechos humanos. Bogotá: Organización de las Naciones Unidas; Molina, G. (2008). Derechos humanos fundamentación, obligatoriedad y cumplimiento. Bogotá: Universidad Libre; Manili, P. (2012). Manual Interamericano de Derechos Humanos. Bogotá: Ediciones Doctrina y Ley Ltda.

13 Véase: Botero, J. F. (2011). Derecho penal internacional protector de los derechos humanos. Revista de relaciones internacionales, 6 (1), 169- 190; Velásquez, J. D. (2013). El derecho natural en la declaración de los derechos humanos. Revista Facultad de Derecho y Ciencias Politicas, 43 (119), 735-772. 
que se relacionan entre sí. En primer lugar, se tiene un hecho, donde el Palacio de Justicia es tomado por un grupo armado ilegal como un hecho de guerra del conflicto armado colombiano. En segundo lugar, después hubo una retoma del Palacio que trajo como consecuencia, delitos como homicidios y desapariciones forzadas, los cuales serían catalogados como delitos de lesa humanidad, y con ellos nace el término de la imprescriptibilidad para instaurar las acciones judiciales respectivas. Bajo la temática de la responsabilidad nacen la imputación del delito de terrorismo y la responsabilidad del Estado ante organismos internacionales.

\section{CONCLUSIONES}

La mayoría de los textos develan una narración de hechos de lo acaecido en el Palacio de Justicia para esa época. Traen recuento de las diferentes versiones de los familiares de las víctimas, de las víctimas directas, de los guerrilleros del M-19, traen a colación investigaciones posteriores a los sucesos acaecidos entre 6 y 7 de noviembre de 1985, y también hablan de los sucesos que circundaron la toma del palacio de justicia por parte del grupo armado y otras investigaciones explican de cómo (...) "la decisión de reparar, la creación de mecanismos especiales y transitorios e iniciativas de reinserción y desmovilización teniendo como referente central los derechos de las víctimas son importantes para las diferentes investigaciones." (Torregrosa y Torregrosa, 2013: 91).

Muy pocos autores exponen en sus narrativas la falta de justicia y verdad en los hechos acaecidos en el Palacio de Justicia o proponen un tema de corte jurídico respecto de los sucesos de ese día, constituyéndose así en fuentes documentales donde cuentan más hechos históricos con versiones de los sujetos de la época.

En cuanto a información extranjera de los hechos del Palacio de Justicia, lo tomaron como un hecho histórico, donde existieron violaciones a los derechos humanos por parte del Estado colombiano.

Se observa que los temas específicos de los trabajos de investigación se dirigen, en mayor medida, a hacer un relato de los sucesos acaecidos en el Palacio de Justicia, un análisis de los hechos planteándolo como acto terrorista, y cómo en este se violaron derechos humanos tanto a los empleados del palacio como a los mismos integrantes del grupo armado M-19.

Finalmente, el Estado colombiano ha suscrito y ratificado diferentes convenios y tratados que versan sobre derechos humanos, los cuales ingresan a 

del Estado frente a los derechos humanos

nuestro ordenamiento jurídico bajo el concepto de bloque de Constitucionalidad contemplado en el artículo 93 de la Constitución colombiana y adquieren el rango de nivel Constitucional, razón por la cual el Estado colombiano tendría cierta responsabilidad ante organismos internacionales.

La falla del servicio es una responsabilidad subjetiva pero cuando pasa al ámbito internacional, la Corte Interamericana de Derechos Humanos aplica el régimen objetivo de responsabilidad porque el Estado colombiano no ha cumplido con los tratados suscritos y ratificados.

Las víctimas que sufran un daño tienen derecho a la verdad, a la justicia y a ser reparadas integralmente por el Estado colombiano, en el caso de comprobarse su responsabilidad en los hechos.

\section{REFERENCIAS}

Abello, R. (2015). Derecho internacional: varias visiones, un maestro. Bogotá: Editorial Universidad del Rosario.

Acosta, M. (Director). (2012). El Palacio de Justicia [DVD]. Bogotá: FM Entretenimiento.

Alonso, M. C. \& Leiva, E. (2012). La responsabilidad del estado por la actividad del legislador. Revista derecho del estado, (29), 145-173.

Aguilar, G. (2009). La reparación civil en casos de violación a Los derechos humanos y la imprescriptibilidad de la Acción civil. Revista derecho del Estado, (22), 7-67.

Amaya, A. F. (2006). La toma del palacio de justicia: la reparación del daño en eventos de violación de derechos humanos. vniversitas (112), 317-349.

Behar, O. (1986). Las guerras de la paz. Bogotá: Editorial Planeta.

Behar, O. (1988). Noches de Humo: Como se Planeó y Ejecutó la toma al Palacio de Justicia. Bogotá: Editorial Planeta.

Behar, O. (2010). Noches de Humo. Revista Nueva Época, 16 (35), 212-227.

Bernal, C. (2010). Metafísica de los derechos humanos. Revista derecho del estado (25), 117-133.

Botero, J. F. (2011). Derecho penal internacional protector de los derechos humanos. Revista de relaciones internacionales, 6 (1), 169- 190. 
Camargo, P.P. (2013). Derecho Internacional Humanitario (5a . Ed.). Bogotá: Editorial Leyer.

Camargo, P.P. (2013). Manual de derechos humanos (4ª . Ed.). Bogotá: Editorial Leyer.

Carrisoza, M., Cordi, J., Ospina, C., Serje, M. C., y Guerrero, C.I. (1985). Condicionamientos histórico- estructurales de la toma del palacio de justicia. Revista Vniversitas, 14(31), 19- 27.

Carrillo, J. M. (2001). La Responsabilidad Administrativa. Bogotá: Universidad Externado de Colombia.

Defensa de los derechos humanos en América Latina: avances y retrocesos. (2009). Quito: Universidad Andina Simón Bolívar-Ecuador. Programa Andino de Derechos Humanos.

Derechos humanos en América Latina. (1993). Perfiles Liberales, 42, 32.

Derechos humanos en América Latina: organizado por el Instituto Latinoamericano de Investigaciones Sociales / Seminario Internacional sobre Derechos Humanos en América Latina. (1979). Bogotá: ALDHU; ILDIS.

Eslava, C. E. (1979). La responsabilidad extracontractual del estado (tesis de grado). Universidad Externado de Colombia. Facultad de Ciencias Jurídicas, Bogotá.

Gamboa, E. (2014). La carga de mitigar los daños en el régimen colombiano de la responsabilidad civil extracontractual. Revista de derecho privado, (51), 1-23.

Gil, E. (2013). Responsabilidad extracontractual del Estado (6ª . ed.). Bogotá: Editorial Temis.

Gil, E. (2014). La constitucionalización del derecho de daños: nuevo sistema de daños en la responsabilidad extracontractual del Estado. Bogotá: Editorial Temis.

Gil, E. (2015). Tesauro de responsabilidad extracontractual del Estado: jurisprudencia 20122014. Bogotá: Editorial Temis.

Gómez, J.A. (2010). Informe final de la Comisión de la Verdad sobre los hechos del Palacio de Justicia. Bogotá: Editorial Universidad del Rosario.

Güechá, C. N. (2012). Falla en el servicio: una imputación tradicional de responsabilidad del estado. Prolegómenos derecho y valores, 15 (29), 95-109.

Güechá, C.N. (2012). Responsabilidad del Estado por actos de terrorismo. Bogotá: Grupo Editorial Ibáñez. 
Henao, J. C. (1991). Prólogo. Gustavo de Greiff Restrepo: La responsabilidad extracontractual del Estado en Colombia: evolución jurisprudencial, 1864-1990. Bogotá: Universidad Externado de Colombia.

Henao, J. C. (2007). El daño: análisis comparativo de la responsabilidad extracontractual del Estado en derecho colombiano y francés. Bogotá: Universidad Externado de Colombia.

Hernández, G. (2010). La justicia en llamas. Revista Nueva Época, 16 (35), 236- 245.

Holguín, J. (1948). La responsabilidad civil de la administración (tesis de grado), Colegio Mayor de Nuestra Señora del Rosario. Facultad de Ciencias Jurídicas, Bogotá.

Hoyos, R. (2006). Responsabilidad del Estado por el uso de las armas de fuego: su incidencia en el presupuesto del Ministerio de Defensa y de la Policía Nacional. Prolegómenos: derechos y valores, 9 (18), 77- 110.

Jimenez, C. (1986). El Palacio de Justicia y el derecho de gentes. Bogotá: La Procuraduría.

Jiménez, R. (1999). Toma del Palacio de Justicia: noviembre 6 de 1985. Revista Credencial historia, (117), 14.

Leal, S. (2013). El Holocausto del Palacio de Justicia: nombres, versiones y desacuerdos. Bogotá: Universidad Nacional de Colombia.

Leal, S. (2010). Reflexiones en torno a una fecha. Revista Nueva Época, 16 (35), 207211.

López, J. M. (2010). El holocausto del Palacio de Justicia. Revista Nueva Época, 16 (35), 228- 235.

López, J. (1996). Responsabilidad del Estado por error judicial: su regulación en el derecho colombiano, doctrina y legislación extranjera. Bogotá: Ediciones Doctrina y Ley.

López, J. (1997). Responsabilidad patrimonial del Estado: evolución de la jurisprudencia colombiana. Bogotá: Ediciones Doctrina y Ley.

Manili, P. (2012). Manual interamericano de derechos humanos. Bogotá: Ediciones doctrina y ley Ltda.

Martínez, J.R. (2014). Derecho internacional y terrorismo. Bogotá: Universidad del Rosario.

Molano, L.S. (1983). La responsabilidad extracontractual del estado (tesis de grado), Colegio Mayor de Nuestra Señora del Rosario. Facultad de Ciencias Jurídicas, Bogotá. 
Molina, C.M. (2004). La responsabilidad extra-contractual del estado por error judicial en Colombia. Opinión jurídica, 3 (6), 13- 35.

Molina, G. (2008). Derechos humanos fundamentación, obligatoriedad y cumplimiento. Bogotá: Universidad libre.

Noticiero Todelar. (2006). Buscando la verdad [registro sonoro 1 compact disc]. Bogotá.

Ruiz, W. (2008). Responsabilidad extracontractual: frente a: Estado legislador, medios de comunicación, responsabilidad fiscal, desplazamiento forzado, actos terroristas. Bogotá: Ecoe Ediciones.

Ruiz, W. (2010). Responsabilidad del Estado y sus regímenes. Bogotá: Ecoe Ediciones.

Ruiz, W. (2011). Prólogo. Germán Vargas Lleras: Responsabilidad del Estado y legislador. Bogotá: Universidad Libre.

Ruiz, W. (2013). Responsabilidad del Estado y sus regímenes (2a . ed.). Bogotá: Ecoe Ediciones.

Serrano, L.G. (2014). La responsabilidad patrimonial del Estado. Bogotá: Ediciones Doctrina y Ley.

Suárez, J. J. (2013). Derechos humanos y naturaleza humana una cuestión no superada. Dikaion, 22 (2), 181- 185.

Torregrosa, N. y Torregrosa, R. (2013). Violencia política en Colombia: algunas pistas para su entendimiento. Verba Iuris. No.30. Universidad Libre. Bogotá.

Torregroza, J.E. (2007). Responsabilidad extracontractual del Estado por el hecho del legislador. Bogotá: Universidad Externado de Colombia.

Varela, M.L. (1978). Responsabilidad del Estado (tesis de grado), Universidad Externado de Colombia. Facultad de Ciencias Jurídicas, Bogotá.

Velásquez, C. (2011). Responsabilidad contractual y extracontractual del Estado: jurisprudencia de la sección tercera del consejo de estado año 2011. Medellín: Librería Jurídica Sánchez R.

Velásquez, F. (2010). Los aparatos criminales organizados de poder. Revista de derecho penal, (4), 173- 190. 
Velásquez, J. D. (2013). El derecho natural en la declaración de los derechos humanos. Revista Facultad de Derecho y ciencias políticas, 43 (119), 735- 772.

Verduga, C. (1988). Democracia y derechos humanos en América Latina. Quito: Ediciones Culturales UNP. 